\title{
Histopathologically-Diagnosed Splenic Metastasis in a Hepatocellular Carcinoma Case with Adrenal Metastasis
}

\author{
Kenji Hanada, Akiko Saito, Hideki Nozawa, Koichi HaruYama, Naoaki HaYashi, \\ Michiyo YAMAdA*, Satoshi KATAgIRI*, Hideo KATSURAGAWA*, \\ Takehito OTSUBO* and Ken TAKASAKI*
}

\begin{abstract}
We encountered a patient with hepatocellular carcinoma (HCC), with adrenal gland metastasis, in whom splenic metastasis was diagnosed histopathologically. A 59-year-old man visited our hospital in May 2001 with chief complaints of abdominal distension and pretibial pitting edema. Multiple HCCs associated with HCVpositive liver cirrhosis were detected. Transarterial embolization (TAE) was performed a total of 4 times for HCCs. A left adrenal gland metastatic lesion was detected and it was found to increase in diameter from $3 \mathrm{~cm}$ to $6 \mathrm{~cm}$ over a four-month period; left adrenalectomy was performed in June 2002. Because of marked splenomegaly and findings of hypersplenism, the spleen was also resected. Although no metastatic lesions were evident on macroscopic examination of the spleen, a small metastatic lesion from moderately differentiated HCC, approximately $0.5 \mathrm{~mm}$ in diameter, was detected histopathologically. Splenic metastasis from HCC is rare, usually occurring with metastases involving other organs. Our patient also had adrenal gland metastasis. Therefore, hematogenous metastasis to the congested spleen via the systemic circulation was suspected.

(Internal Medicine 43: 484-489, 2004)
\end{abstract}

Key words: hepatocellular carcinoma, splenic metastasis, adrenal metastasis

\section{Introduction}

The most common form of metastasis from HCC is intrahepatic and is via the portal vein, followed by hematogenous metastasis to the lungs and bone, lymph node metastasis, and peritoneal metastasis. Metastasis to the spleen is rare (1). We encountered a case of HCC with adrenal gland metastasis, in whom histopathological examination also revealed a small metastatic lesion in the resected spleen.

\section{Case Report}

The patient was a previously asymptomatic 59-year-old man. His father had died of hepatic cancer of unknown histology. In 1988, a routine health check-up had revealed liver function abnormalities. In 1993, hepatitis C was diagnosed and thereafter he was followed up regularly. The patient, however, discontinued his visits to the hospital in 1998. In May 2001, he returned with chief complaints of abdominal distension and pretibial pitting edema. Abdominal ultrasonography (US) revealed a space-occupying lesion in the liver, and he was referred to our department. Abdominal US and computed tomography (CT) revealed multiple tumors in both lobes of the liver, and HCC with underlying liver cirrhosis was diagnosed. Transarterial embolization (TAE) was performed after hospitalization a total of 4 times between July 2001 and March 2002. A left adrenal gland metastasis detected in January 2002 increased from $3 \mathrm{~cm}$ to $6 \mathrm{~cm}$ in diameter during the next four months. In June 2002, the patient was admitted, for a fifth time, for surgery.

\section{Status on admission}

Height, $167 \mathrm{~cm}$; weight, $82 \mathrm{~kg}$; no anemia or jaundice; liver and spleen not palpable; pretibial pitting edema present; no neurological abnormalities.

\section{Laboratory data}

A complete blood count revealed decreases in platelets and red blood cells. Serum biochemical tests revealed increases in serum transaminase levels, with a marked increase in serum aspartate aminotransferase (AST), elevated biliary

From the Departments of Gastroenterology and *Gastroenterological Surgery, Tokyo Women's Medical University, Tokyo

Received for publication April 9, 2003; Accepted for publication January 23, 2004

Reprint requests should be addressed to Dr. Akiko Saito, the Department of Gastroenterology, Tokyo Women's Medical University, 8-1 Kawada-cho, Shinjuku-ku, Tokyo 162-8666 
HCC Splenic Metastasis

Table 1. Laboratory Data on Admission

\begin{tabular}{|c|c|c|c|c|c|}
\hline \multicolumn{2}{|c|}{ Hematology } & $\underline{\mathrm{LDH}}$ & $548 \mathrm{IU} / \mathrm{l}$ & Serological test & \\
\hline WBC & $2,300 / \mu \mathrm{l}$ & $\overline{\mathrm{ALP}}$ & $427 \mathrm{IU} / \mathrm{l}$ & HBs-Ag & $(-)$ \\
\hline$\overline{\mathrm{Hb}}$ & $13.7 \mathrm{~g} / \mathrm{dl}$ & $\overline{\gamma \mathrm{GTP}}$ & $125 \mathrm{IU} / \mathrm{l}$ & HBs-Ab & $(-)$ \\
\hline $\mathrm{Ht}$ & $41.9 \%$ & Ch-E & $132 \mathrm{IU} / \mathrm{l}$ & $\mathrm{HCV}-\mathrm{Ab}$ & $(+)$ \\
\hline Plt & $3.0 \times 10^{4} / \mu \mathrm{l}$ & BUN & $13.0 \mathrm{mg} / \mathrm{dl}$ & Tumor marker & \\
\hline \multicolumn{2}{|c|}{ Blood chemistry } & $\mathrm{Cr}$ & $0.99 \mathrm{mg} / \mathrm{dl}$ & AFP & $11 \mathrm{ng} / \mathrm{ml}$ \\
\hline $\mathrm{TP}$ & $6.5 \mathrm{~g} / \mathrm{dl}$ & ICG R15 & $66 \%$ & $\overline{\mathrm{L} 3}$ & $13.2 \%$ \\
\hline $\mathrm{Alb}$ & $2.8 \mathrm{~g} / \mathrm{dl}$ & Coagulation & & PIVKAII & $224 \mathrm{mAU} / \mathrm{ml}$ \\
\hline T-Bil & $1 . \overline{\mathrm{mg} / \mathrm{dl}}$ & $\%$ PT & $78.3 \%$ & $\overline{\mathrm{CEA}}$ & $0.6 \mathrm{ng} / \mathrm{ml}$ \\
\hline$\overline{\mathrm{AST}}$ & $130 \mathrm{IU} / \mathrm{l}$ & $\overline{\overline{\mathrm{HPT}}}$ & $\overline{50.8 \%}$ & CA19-9 & $17 \mathrm{U} / \mathrm{ml}$ \\
\hline$\overline{\mathrm{ALT}}$ & $91 \mathrm{IU} / \mathrm{l}$ & $\overline{\mathrm{TT}}$ & $\overline{46.5 \%}$ & & \\
\hline
\end{tabular}

enzymes, and an ICGR15 increase. As to tumor markers, serum AFP was mildly elevated and PIVKA II was also increased (Table 1).

\section{Abdominal CT}

Five to $30 \mathrm{~mm}$ low-density nodules were noted at six sites in both lobes of the liver at the first examination. They were seen as high-density areas in the early phase and low-density areas in the late phase of a contrast-enhanced imaging study, and a diagnosis of multiple HCCs was made. At the most recent examination on admission, accumulation of lipiodol after TAE and several viable HCCs, ranging from 5 to 20 $\mathrm{mm}$ in size, were observed in both lobes of the liver (Fig. $1 \mathrm{~A})$. The spleen was markedly enlarged, but no metastatic lesions were detected (Fig. 1A). A tumor, $6 \mathrm{~cm}$ in diameter, which showed uneven contrast enhancement, was seen in the left adrenal gland but this tumor did not obstruct the splenic vein. (Fig. 1B).

\section{Clinical course after admission (Fig. 2)}

The adrenal gland tumor showed a rapid increase in size, associated with serum PIVKA II elevation. Multiple HCCs were observed within the liver, but there were no tumor thrombi in the portal vein. Esophageal varices were absent, and the patient's general condition was reasonably good. A left adrenalectomy was performed, to avoid tumor rupture, in June 2002. Since features of hypersplenism were noted, splenic resection was also performed. As the patient was classified as having Grade B according to the Child-Pugh classification, a medical approach including TAE was planned for management of the intrahepatic tumors postoperatively.

\section{Macroscopic findings of the resected specimen}

The adrenal gland tumor was a solid mass of elastic consistency, with a relatively smooth surface. The cut surface revealed a mosaic of large and small encapsulated whitish nodules (Figs. 3A). The spleen was enlarged, but there were no metastatic lesions macroscopically and no findings indicative of splenic vein obstruction (Figs. 4A).

\section{Histopathological findings in the resected specimen}

Adrenal gland metastasis was diagnosed, based on the trabecular pattern, along with moderately differentiated HCC (Fig. 3B HE stain, $\times 400$ ). A small metastatic lesion, measuring $0.5 \mathrm{~mm}$ in diameter, from a moderately differentiated HCC was also observed at the splenic hilus (Fig. 4B HE stain, $\times 100)$. There were no other metastatic lesions in any of the splenic slice specimens examined.

\section{Discussion}

In both autopsy cases and in those with recurrence after surgery, the main forms of metastasis of HCC are intrahepatic and occur via the portal vein while distant metastasis is via arteries to the lungs, adrenal glands and bone (1-5). The reported prevalences of adrenal gland metastasis of $\mathrm{HCC}$ range from 8.3 to $12.5 \%$ (1-5). Splenic metastasis is reportedly seen in 1.0 to $5.6 \%$ of $\mathrm{HCC}$ cases $(2,5)$, and can be divided into disseminated, hematogenous and lymphogenous types. Hematogenous metastasis, in particular, is very rare with a reported prevalence of $0.7 \%$ (6). Possible reasons for the low prevalence of splenic metastasis include the extremely small number of afferent lymph ducts in the spleen, ejection of malignant cells due to rhythmic contraction of the spleen, and immunological obstacles to intrasplenic growth of malignant cells since the spleen is an organ of the reticuloendothelial system $(7,8)$. However, the precise reasons remain to be clarified.

As to routes of metastasis to the spleen, since splenic metastasis is often observed in the setting of systemic metastasis in autopsy cases, hematogenous metastasis is probably more common than lymphogenous metastasis. Metastases via the portal vein and via the systemic circulation to the splenic artery are possible routes of hematogenous metastasis. One report suggested that splenic metastasis may occur via the portal vein, based on the presence of hepatofugal blood flow in the main branch of the portal vein (9). In the present patient, color Doppler sonography did not show retrograde portal blood flow. Moreover, a metastatic lesion in the adrenal gland showed a rapid increase in size. Therefore, splenic metastasis via the systemic circulation to the splenic artery appeared to be very likely. Furthermore, marked splenomegaly 


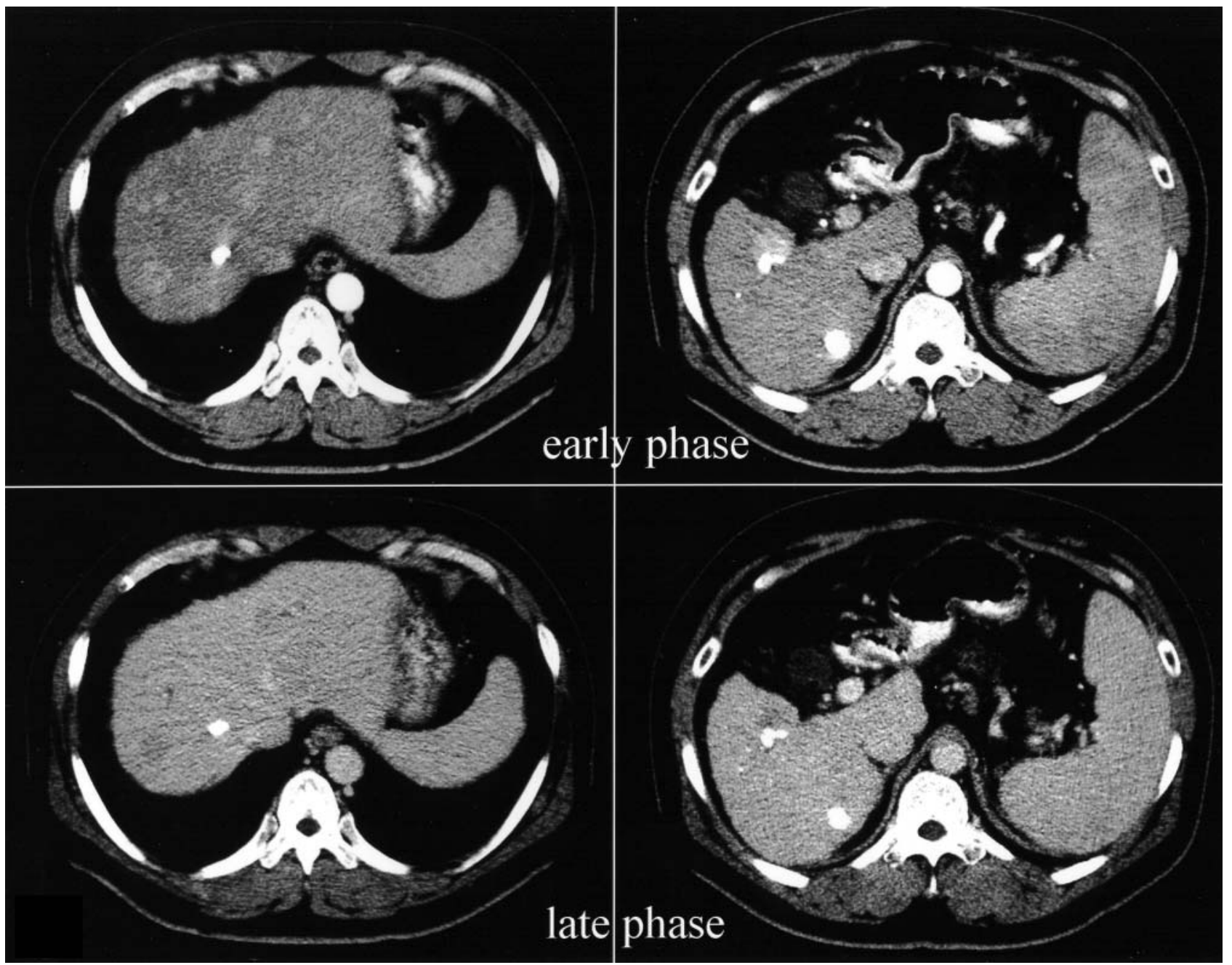

A
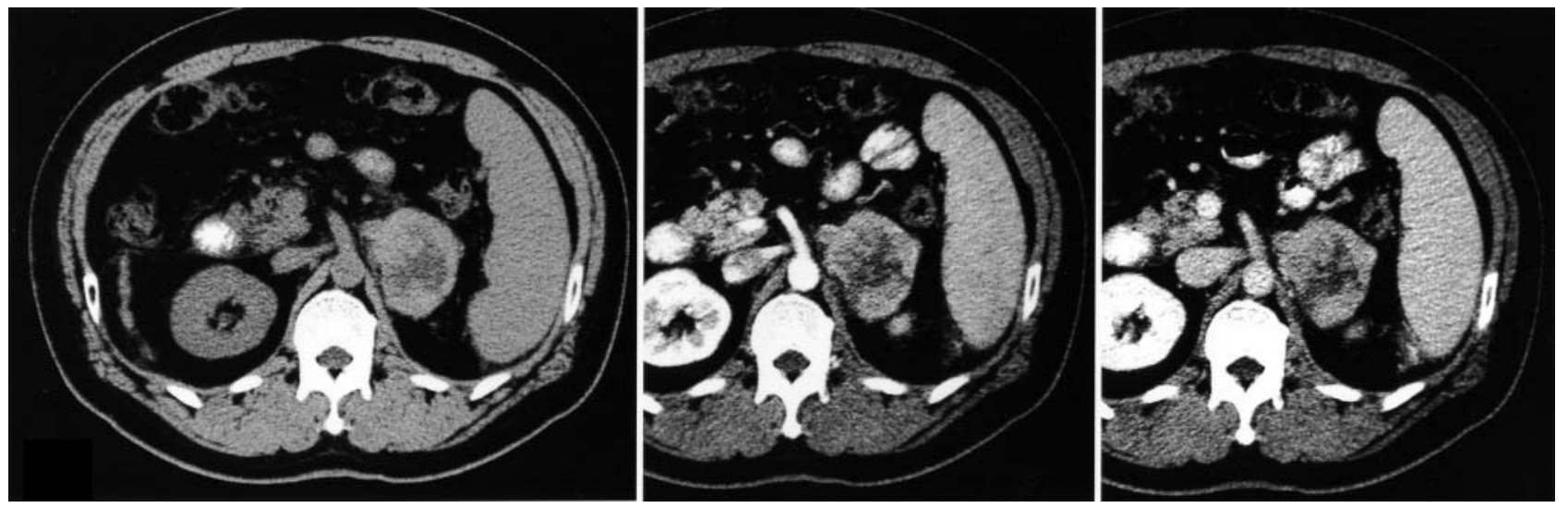

B

Figure 1. Abdominal CT at the most recent admission (May 2002). Nodules with lipiodol accumulation after TAE and several viable HCCs are observed in both lobes of the liver (Fig. 1A). The left adrenal tumor diameter has increased to approximately $6 \mathrm{~cm}$ (Fig. 1B). Despite splenomegaly, there are no obvious metastatic lesions (Fig. 1C). 


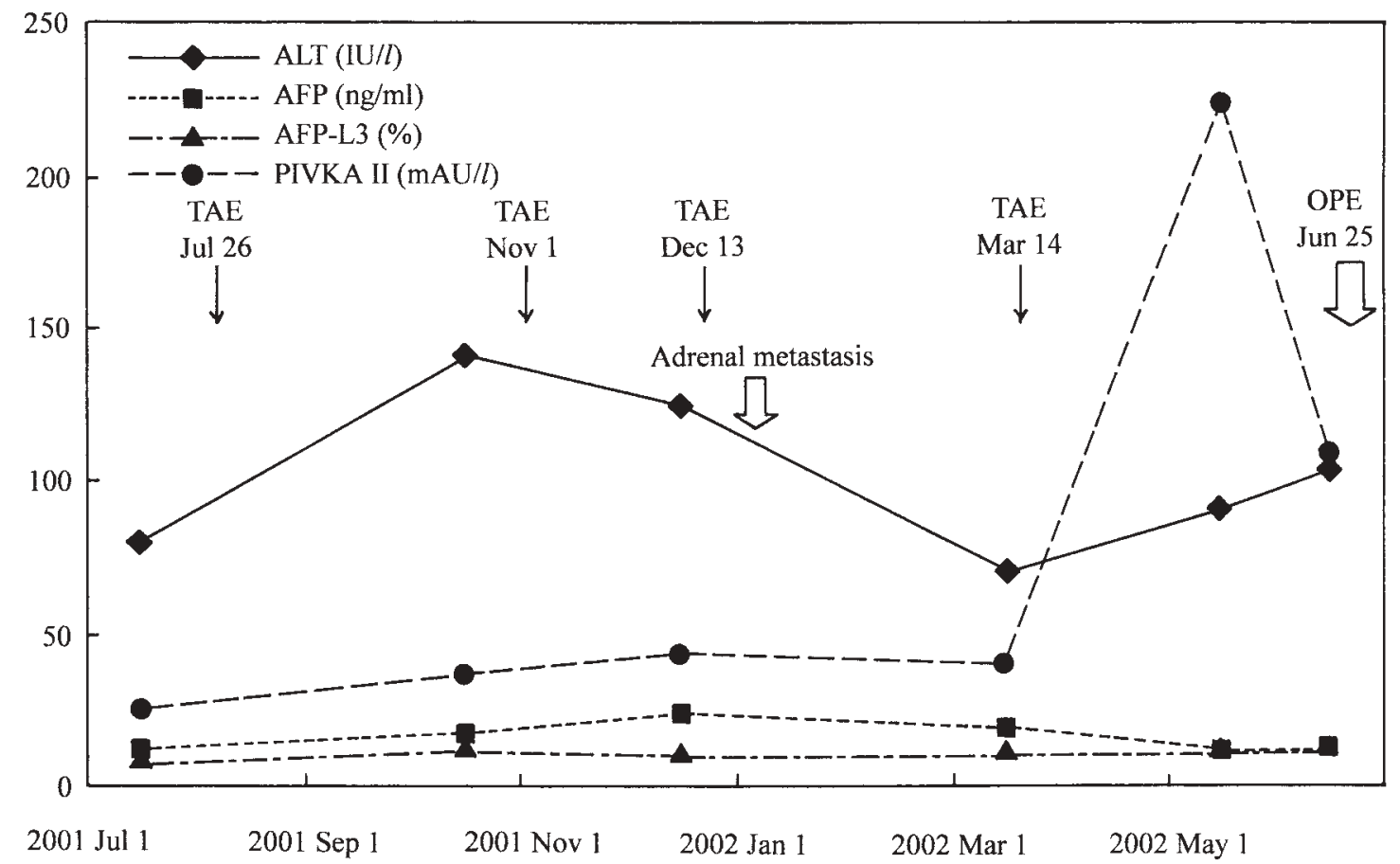

Figure 2. Clinical course after admission.
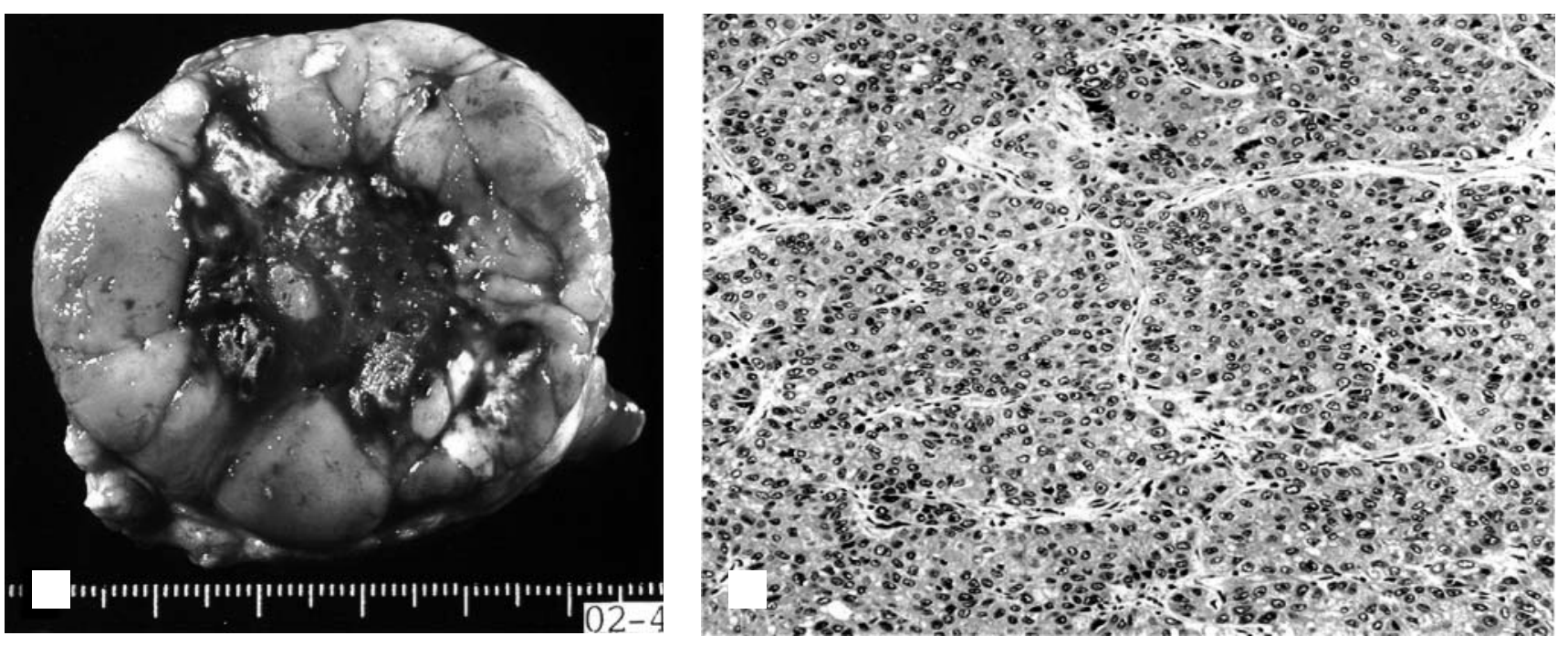

Figure 3. The resected left adrenal gland specimen. The adrenal gland tumor is a solid mass, $65 \times 45 \mathrm{~mm}$. A cluster of white nodules can be seen in cut sections (Fig. 3A). Histopathologically confirmed as a moderately differentiated HCC (Fig. 3B).

and congestion of the spleen, as revealed by histopathological examination of the resected specimen, may have created an environment conducive to implantation of HCC.

To date, splenic metastases arising from HCCs have been resected in three patients managed at our facility (Table 2). Although untreated intrahepatic metastases were also detected at the time of diagnosis of the splenic metastasis only in our present case, metastases to other organs were present in this case and in one other case treated at our institution. In the present case, splenic metastasis was diagnosed histopathologically, by chance, in a specimen resected during surgery for adrenal gland metastasis. Although splenic metastasis from HCCs is considered to be rare, our experience suggests that such metastatic lesions may be histologically 

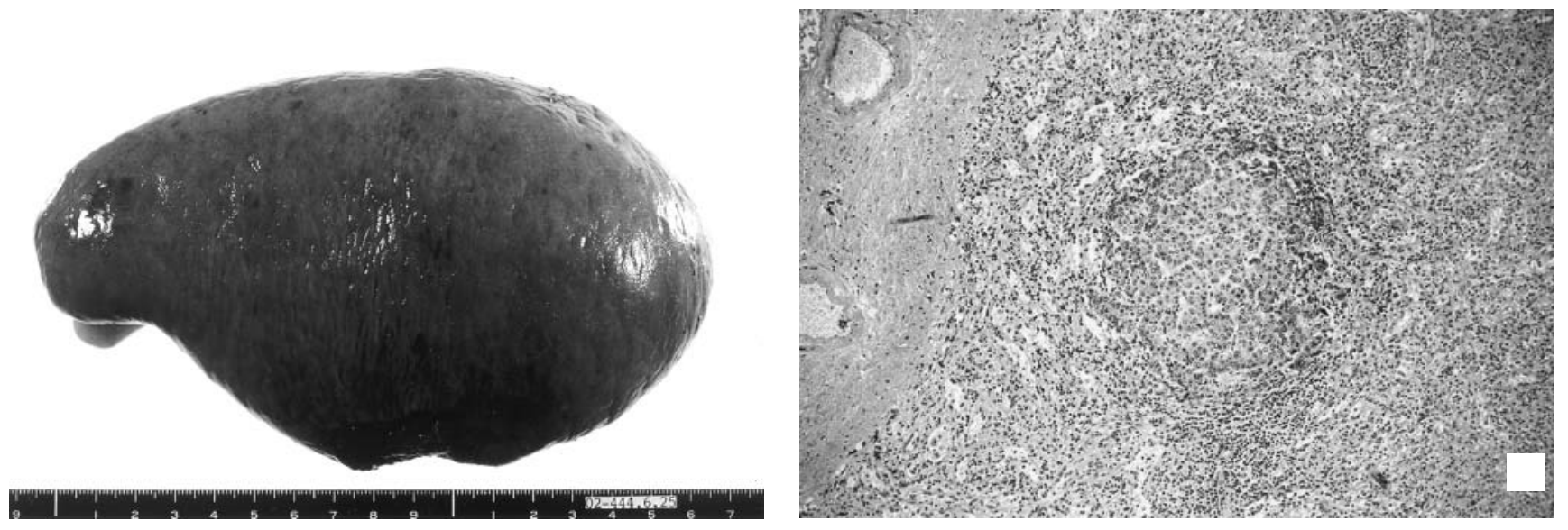

Figure 4. Histopathological findings of the resected specimen. No metastatic lesions are evident on macroscopic examination of the spleen (Fig. 4A). A $0.5 \mathrm{~mm}$, moderately differentiated HCC was detected histopathologically at the hilus of the spleen (Fig. 4B).

Table 2. Cases with Resection of Splenic Metastasis from HCC

\begin{tabular}{|c|c|c|c|c|c|c|c|c|}
\hline Age & Sex & Etiology & $\begin{array}{l}\text { Primary HCC } \\
\text { lesion }\end{array}$ & Treatment & $\begin{array}{l}\text { Intrahepatic metastasis } \\
\text { at time of splenic } \\
\text { metastasis }\end{array}$ & $\begin{array}{l}\text { Period until } \\
\text { splenic } \\
\text { metastasis }\end{array}$ & $\begin{array}{l}\text { Metastasis to } \\
\text { another } \\
\text { organ }\end{array}$ & Outcome \\
\hline 69 & $\mathrm{~F}$ & NBNC & $\begin{array}{l}13 \mathrm{~cm} \text { in diameter, } \\
\text { Right lobe }\end{array}$ & Operation & None & 6 months & None & $\begin{array}{l}20 \text { months: } \\
\text { death }\end{array}$ \\
\hline 67 & M & $\mathrm{CH}-\mathrm{C}$ & $\begin{array}{l}13 \mathrm{~cm} \text { in diameter, } \\
\text { Left lobe }\end{array}$ & $\begin{array}{l}\text { Operation } \\
\& \mathrm{TAE}\end{array}$ & None & 71 months & Lung & $\begin{array}{l}2 \text { months: } \\
\text { alive }\end{array}$ \\
\hline $59 *$ & $\mathrm{M}$ & LC-C & Multiple & TAE & Multiple HCCs & 10 months & $\begin{array}{l}\text { Adrenal } \\
\text { gland }\end{array}$ & $\begin{array}{l}2 \text { months: } \\
\text { death }\end{array}$ \\
\hline
\end{tabular}

*: This case. Out of 1,100 resected HCC cases at our facility (1990-2002).

detectable in a considerable number of cases with both intrahepatic metastasis and metastases to other organs.

Since metastasis to the spleen is only occasionally observed in cases with advanced HCC, reports of treated cases are rare. Splenectomy should perhaps be recommended in some cases, as a case of splenic rupture has been reported (10). However, only intrahepatic tumors and rapidly growing metastatic lesions involving other organs appear to affect outcome, such that a microscopic splenic metastasis would very unlikely be of prognostic significance.

The cumulative survival rates of stage IVB patients who had HCC with both intrahepatic and extrahepatic disease were very poor, $55.7 \%$ at 1 year, $26.5 \%$ at 3 years, and $15.5 \%$ at 5 years (11). On the other hand, the cumulative survival rates of patients undergoing adrenalectomy after curative treatment for primary HCC were better, 68\% at 1 year, $34 \%$ at 3 years, and $34 \%$ at 5 years (12). In the present case, whose untreated intrahepatic metastases remained even after resection of adrenal and splenic metastases, the prognosis was thought to be poor.

\section{References}

1) Hoyne RM, Kernohan JW. Primary carcinoma of the liver. A study of thirty-one cases. Arch Int Med 79: 532-554, 1947.

2) Edmondson HA, Steiner PE. Primary carcinoma of the liver. A study of 100 cases among 48,900 necropsies. Cancer 7: 462-503, 1954.

3) Nakashima T, Okuda K, Kojiro M, et al. Pathology of hepatocellular carcinoma in Japan. 232 consecutive cases autopsied in ten years. Cancer 51: 863-877, 1983.

4) The Liver Cancer Study Group of Japan. Primary liver cancer in Japan. Clinicopathologic features and results of surgical treatment. Ann Surg 211: 277-287, 1990.

5) Katyal S, Oliver JH III, Peterson MS, Ferris JV, Carr BS, Baron RL. Extrahepatic metastases of hepatocellular carcinoma. Radiology 216: 698-703, 2000.

6) Nakashima T, Kojiro M, Sugihara S, et al. A study of extrahepatic metastasis in hepatocellular carcinoma. Kurume Igakukaizasshi 47: 468473, 1984 (in Japanese).

7) Marymont JH Jr, Gross S. Pattern of metastatic cancer in the spleen. Am J Clin Pathol 40: 58-66, 1963.

8) Wareen S, Davis AH. Studies on tumor metastasis, V. The metastasis of carcinoma to the spleen. Am J Cancer 21: 517-533, 1934.

9) Takeuchi H, Konaga E, Nishina T, et al. A case of spontaneous rupture 


\section{HCC Splenic Metastasis}

of the spleen secondary to metastatic hepatocellular carcinoma. Kan tan sui 24: 659-662, 1992 (in Japanese).

10) Horie $Y$, Suou T, Hirayama $C$, Nagasako R. Spontaneous rupture of the spleen secondary to metastatic hepatocellular carcinoma: A report of a case and review of the literature. Am J Gastroenterol 77: 882-884, 1982.
11) The Liver Cancer Study Group of Japan. The general rules for the clinical and pathological study of primary liver cancer (The 4th edition). 93, 2001.

12) Momoi $H$, Shimahara $Y$, Terajima $H$, et al. Management of adrenal metastasis from hepatocellular carcinoma. Surg Today 32: 1035-1041, 2002. 